\title{
Proton MR SpeCtroscopy in Brain METABolic Disorders
}

\author{
Nicola De Stefano, MD
}

\author{
Department of Neurological and Behavioural Sciences \\ University of Siena
}

\begin{abstract}
Metabolic disorders of the central nervous system (CNS) include pathologies with extremely different pathogenesis. The clinical diagnosis of these disorders is often very difficult and requires sophisticated laboratory investigations. Proton magnetic resonance (MR) spectroscopy ( ${ }^{1} \mathrm{H}-\mathrm{MRS}$ ) has been recently used in a number of clinical studies to supplement conventional MRI as it is able to provide in vivo biochemical assay of a given brain tissue. Brain data on several neurometabolic diseases suggest that ${ }^{1} \mathrm{H}$-MRS can provide in vivo chemical-pathological characterization of the abnormality detected by MRI and can detect metabolic alterations in tissue appearing normal on conventional MRI. This may help for differential diagnosis and can be important in the evaluation of disease outcome. Indices provided by ${ }^{1} \mathrm{H}-\mathrm{MRS}$ have been demonstrated to be relevant to patients' clinical status, to represent sensitive indicators of early neurological involvement and to be helpful in monitoring effects of therapeutic interventions. This suggests that, in the next future, a more extensive use of brain ${ }^{1} \mathrm{H}-\mathrm{MRS}$ in the management of patients with metabolic disorders affecting CNS should be encouraged.
\end{abstract}

Keywords: magnetic resonance spectroscopy, metabolism, white matter

\section{INTRODUCTION}

The advent of magnetic resonance (MR) imaging (MRI) has changed the clinical approach to the evaluation of the metabolic disorders. The clinical importance of MRI in the management of patients with metabolic disorders of the central nervous system (CNS) lies in its great sensitivity for detecting brain lesions. However, unfortunately, the brain lesions detected on MRI are often not characteristic enough to allow the diagnosis of these complex disorders [1]. In recent years, nonconventional MR techniques have been used to complement conventional MRI and overcome some of its limitations. Proton MR spectroscopy $\left({ }^{1} \mathrm{H}\right.$-MRS) has been particularly useful in patients with metabolic disorders as it can simultaneously provide chemical-pathological correlates of changes occurring within and outside visible MRI lesions. Thus, an expanding number of research groups have been using single voxel ${ }^{1} \mathrm{H}-\mathrm{MRS}$ and multivoxel MR spectroscopic imaging $\left({ }^{1} \mathrm{H}\right.$-MRSI) in vivo to study patients with metabolic disorders [2-4]. These ${ }^{1} \mathrm{H}$-MRS techniques have demonstrated to increase diagnostic accuracy and the understanding of the evolution of pathology in many of these disorders It must also be stressed, however, that ${ }^{1} \mathrm{H}$-MRS is complementary to MRI, except in a few cases where a disease-specific pattern could be detected.

We will give an overview on how ${ }^{1} \mathrm{H}-\mathrm{MRS}$ can be used as a complementary method to conventional MRI to detect metabolic changes in the most frequently studied metabolic disorders.

\section{DiAgNOSTIC-SPECIFIC ${ }^{1} \mathrm{H}$-MRS CHANGES}

As stated before, the ${ }^{1} \mathrm{H}$-MRS changes detected in metabolic disorders are, in most cases, not disease-specific. However, in some conditions ${ }^{1} \mathrm{H}-\mathrm{MRS}$ can provide typical brain metabolic patterns able to address the diagnosis.

One example of a disease in which MRS provides a diagnostic pattern is a spongiform leukoencephalopathy known as Canavan's disease. In this disorder, the deficiency of the enzyme aspartoacylase (which breaks down NAA) is responsible for abnormally high levels of NAA in the brain, which can be considered pathognomonic $[8 ; 9]$. It must be stressed, however, that high NAA level can be also found in Salla disease and severe infantile sialic acid storage diseases $[10 ; 11]$, but in these conditions the high NAA signal reflects an accumulation of $\mathrm{N}$-acetyl-neuraminic acid that offsets the possible loss of NAA. Moreover, small increases in NAA can be found in patients with PelizaeusMerzbacher disease probably reflecting the elevated density of axons in white matter lacking the oligodendrocytic tissue and normal myelin sheaths between axons [12].

In vanishing white matter disease (VWM, also called childhood ataxia with diffuse CNS hypomyelination) and megalencephalic cystic leukoencephalopathy (MCL) [13-18] conventional MRI findings of extensive white matter abnormalities with sparing of central brain structures are seen together metabolic changes detected with ${ }^{1} \mathrm{H}$-MRS. These changes include the almost complete disappearance of all normally detected 
metabolites in the white matter, presence of small increases in Lac and sparing of gray matter that is structurally and metabolically normal. In MCL, although ${ }^{1} \mathrm{H}$-MRS abnormalities tend to be more pronounced with increasing age, these are generally mild and the frontal white matter is significantly less involved than other white matter regions. In patients with VWM disease, increases in glucose resonance intensities (present at 3.4 and $3.8 \mathrm{ppm}$ ) may also be present. This ${ }^{1} \mathrm{H}-\mathrm{MRS}$ metabolic profile is probably due to little brain white matter tissue left and the great increase in extracellular spaces.

Other rare metabolic conditions also may provide diagnostic-specific ${ }^{1} \mathrm{H}$-MRS findings. In phenylketonuria, patients show a specific peak due to the elevated phenylalanine at $7.37 \mathrm{ppm}$ and, despite the diagnosis is easily reached testing the enzyme involved in the disease, the size of this peak can be used in patients with this metabolic disorder to follow the influx of phenylalanine from blood into brain tissue as well as to monitor the response of diet therapy [19-21]. In the leukoencephalopathy associated with the disturbance of the metabolism of the polyols [22], the diffuse decrease of all normally detected metabolites is associated with the increases of arabitol and sorbitol in both white and grey matter regions. In maple syrup disease, a relatively specific broad peak is detectable at $0.9 \mathrm{ppm}$. This region of the spectrum is usually attributed to lipids, but in maple syrup disease is believed to represent resonances of methyl protons from branched-chain aminoacids and branched-chain alphaketo acids that accumulate as a result of defective oxydative decarboxylation of leucine, isoleucine and valine [23]. Also ${ }^{1} \mathrm{H}$-MRS studies on patients with Niemann-Pick type $\mathrm{C}$ disease have shown increased resonance intensity of the lipid region of the spectrum, probably due, in this case, to a defective metabolism of cholesterol with ceramide accumulation $[24 ; 25]$. In both maple syrup and Niemann-Pick type C diseases, the abnormal broad peak detectable at $0.9 \mathrm{ppm}$ seem to decrease with appropriate therapy $[23 ; 24]$. In nonketotic hyperglycinemia, the elevated glycine signal at 3.55 ppm detected by ${ }^{1} \mathrm{H}$-MRS is particularly meaningful when depicted with long echo time sequences [26; 27]. In this disorder, defective glycine cleavage causes elevated concentrations of glycine in plasma, urine, and cerebrospinal fluid. In earlier studies $[28 ; 29]$, the reduction of glycine in brain tissue corresponded more reliably with clinical findings than the stable values in plasma and cerebrospinal fluid, indicating that ${ }^{1} \mathrm{HMRS}$ can be a valuable tool in the diagnosis and monitoring of treatment effects in patients with this rare disorder. In succinate-dehydrogenase deficiency, a rare cause of mitochondrial encephalomyopathy, the presence of an abnormal peak at $2.4 \mathrm{ppm}$ (originating from the two equivalent methylene groups of succinate) in the cerebral and cerebellar white matter can provide a metabolic pattern distinctive of the disease [30]

Finally, specific metabolic syndromes have been recently revealed by using proton MRS. This is the case of the creatine deficiency syndromes, which include defects in the guanidinoacetate methyltransferase and in the arginine-glycine amidinotransferase $[31 ; 32]$, and the X-linked creatine deficiency syndrome [33]. In the first two forms of the diseases, the Cr resonance intensity is undetectable in the brain on ${ }^{1} \mathrm{H}$-MRS, but cerebral levels of $\mathrm{Cr}$ do increase after creatine supplementation. In the X-linked form of creatine deficiency, as the metabolic defect is due to the transport of creatine into the central nervous system, patients are unresponsive to treatment and the $\mathrm{Cr}$ resonance intensity levels are unchanged after creatine supplementation. Another condition with very specific ${ }^{1} \mathrm{H}$-MRS spectrum is the unique case of a child with minor developmental delay and absence of cerebral NAA, in whom the most prominent peak of ${ }^{1} \mathrm{H}$-MRS at $2.02 \mathrm{ppm}$ was undetectable [34]. Both creatine deficiency syndromes and the absence of NAA are characterized by mild or absent abnormalities on conventional MRI suggesting the unique potential of ${ }^{1} \mathrm{H}$-MRS in revealing metabolic abnormalities in MRI normal-appearing tissue.

\section{${ }^{1}$ H-MRS IN THE DIFFERENTIAL DIAGNOSIS OF MITO- CHONDRIAL DISORDERS}

In the clinical suspect of a mitochondrial disorder, ${ }^{1} \mathrm{H}-$ MRS can offer information useful for the differential diagnosis beyond what is currently available in routine clinical use.

For example, the intra-parenchymal levels of Lac are usually elevated in mitochondrial disorders [3; 35], although it must be also stressed that Lac levels are not unequivocally elevated in all patients and/or in all the brain structures. In general, Lac levels are transiently increased in a number of acute pathological conditions associated with inflammatory cells $[2 ; 36 ; 37]$, but extensive pathological increases in Lac both within and outside of MRI lesions may be indicative of widespread energy failure associated with mitochondrial dysfunction $\left[38\right.$; 39]. In addition, as ${ }^{1} \mathrm{H}-\mathrm{MRS}$ can provide advantages in the interpretation of the pathological processes underlying the brain tissue, this can be used to differentiate brain lesions appearing similar on MRI. That is, much larger increased levels of brain parenchymal Lac can be found in hypoxic-ischemic white matter lesions with a complex pathogenesis such as of the mitochondrial encephalopathy with lactic acidosis and stroke-like episodes (MELAS) than in acute and chronic cerebrovascular disorders [40].

In other very rare metabolic disorders such as the ethylmalonic encephalopathy [41] and a new type of leukoencephalopathy with slowly progressive pyramidal, cerebellar, and often dorsal column dysfunction [42] the findings of diffuse brain mitochondrial impairment have strongly contributed to the interpretation of the complex pathogenetic mechanisms of these disorders. In both cases, the diffuse ${ }^{1} \mathrm{H}$-MRS increase in brain Lac detected in a multi-voxel ${ }^{1} \mathrm{H}$-MRSI study was underlying a primary mitochondrial disorder, as demonstrated by biochemical and genetic studies [43; 44]. Furthermore, in a very rare metabolic disorders such as the cerebrotendinous xanthomatosis, the diffuse ${ }^{1} \mathrm{H}-\mathrm{MRS}$ increase in brain Lac detected in a single- 
voxel ${ }^{1} \mathrm{H}$-MRS study [45] add to morphological and biochemical evidence of mitochondrial dysfunction, probably secondary to the toxic effect of high cholestanol and/or bile alcohol levels [46; 47].

\section{DEMYelinATING AND DISMYELINATING DISEASES}

Myelinogenesis is a complex process that can be altered by various hereditary metabolic defects resulting in disorders that are generically grouped under the term of leukodystrophies. This congenital failure in myelinogenesis is comprehensive of several mechanisms of myelin disruption such as hypomyelination, demyelination, dysmyelination, etc., and is due to very different genetic and biochemical abnormalities, most of which are still undefined [48]. In these conditions, the ${ }^{1} \mathrm{H}$-MRS pattern is often not very specific. However, it might show temporal changes indicative of the metabolic alterations occurring within and outside the abnormalities visible on MRI.

Changes in several metabolites can be seen within demyelinating lesions since the very early phase of the pathological process [6]. Changes in the resonance intensity of Cho result mainly from increases in the steady state levels of phosphocholine and glycerolphosphocholine, both membrane phospholipids released during active myelin breakdown. Increases in Lac are likely to reflect the metabolism of inflammatory cells. In acute demyelination, decreases in $\mathrm{Cr}$ can also be seen [6]. Short echo time spectra give evidence for transient increases in mI [49] and lipids [50], also released during myelin breakdown. After the acute phase, metabolic modifications in the demyelinating lesion show a variable time course [6]. Usually, resonance intensities of $\mathrm{Cr}$ and lipids return to normal within a few days. At this stage, small increase in $\mathrm{Cr}$, due to changes in cellularity, can be found inside the demyelinating lesion [51]. Resonance intensities of Lac show a progressive reduction over a period of weeks, whereas Cho and $\mathrm{mI}$ return to normal in months. The signal intensity of NAA decreases and, later, may remain decreased or may show a partial recovery [52]. Recovery of NAA may be related to resolution of edema, increases in the diameter of previously shrunken axons that are secondary to remyelination and clearance of inflammatory factors, and reversible metabolic changes in neurons [52].

In progressive disorders, such as many leukodystrophies, the loss of myelin can be very slow and released membrane phospholipids might not accumulate. Thus, ${ }^{1} \mathrm{H}$-MRS changes such as those detected in acute demyelination are not seen. In some cases, however, (i.e, adrenoleukodystrophy, Krabbe disease) the high membrane turnover may cause longterm increases in Cho [53]. In contrast, decrease in Cho or increase in $\mathrm{Cr}$ can be detected in hypomyelination [54]. In dysmyelinating diseases such as the Pelizaeus-Merzbacher disease both increases and decreases in Cho have been described $[12 ; 55]$

A number of brain ${ }^{1} \mathrm{H}$-MRS studies of patients with white matter disorders have also shown changes in the relative resonance intensity of $\mathrm{mI}$. The function of $\mathrm{mI}$ in the human brain is not clear, but increases of this metabolite seem to be related to the presence of white matter gliosis and appear consistently in disorders associated with impaired myelination such as adrenoleukodystrophy, metachromatic leukodystrophies, phenylketonuria and Zellweger syndrome [53; 56-58].

Finally, a constant finding of all metabolic disorders affecting the brain white matter is the large decrease in cerebral NAA [3]. This, however, might be mild or absent in hypomyelination [54].

\section{${ }^{1}$ H-MRS TO MONITOR DISEASE OUTCOME AND RE- SPONSE TO THERAPY}

As NAA is found almost exclusively in neurons and their processes in mature brains decreases in this metabolite are interpreted as an index of axonal damage, dysfunction or loss $[59 ; 60]$. Neuro-axonal damage represents the most important substrate of functional impairment in neurological disorders. Thus, it is not surprising that a number of ${ }^{1} \mathrm{H}-\mathrm{MRS}$ studies have demonstrated highly significant correlations between decreasing NAA and increasing clinical disability in patients with many of these disorders [3; 59]. NAA may offer a highly sensitive, clinically-relevant surrogate of pathological change useful for monitoring disease progression [61].

Unfortunately, therapy is not an easy task in the metabolic disorders involving the CNS. Despite this, ${ }^{1} \mathrm{H}-$ MRS has been proposed in trials of patients with adrenoleuokodystrophy [62] and changes over time in levels of NAA have been used s endpoint after aspartoacylase gene transfer [63]. These recent data add to those previously mentioned such as such creatine deficiency [31], mitochondrial disorders [39] and phenylketonuria [64] and other rare conditions, where ${ }^{1} \mathrm{H}$-MRS has been used to monitor response to therapy. In addition, guidelines for a multi-centre use of ${ }^{1} \mathrm{H}$-MRS in clinical trials of multiple sclerosis have been recently provided [65]. All together, these data suggest that ${ }^{1} \mathrm{H}$-MRS can be easily performed in routine clinical settings to monitor treatment, when this is possible.

\section{Conclusions}

${ }^{1} \mathrm{H}$-MRS of the brain provides chemical-pathological information that has the potential to improve both diagnostic classification and management of patients with metabolic disorders affecting the CNS. Metabolic indices provided by ${ }^{1} \mathrm{H}$-MRS could be sensitive indicators of early neurological involvement and are relevant to patients' clinical status. A more extensive use of ${ }^{1} \mathrm{H}$-MRS (possibly with short echo time sequences) in combination with other nonconventional MR techniques might yield a more complete description of the dynamics responsible for pathological changes in this heterogeneous group of disorders and may allow a more accurate evaluation of disease progression and response to therapeutical intervention. 


\section{REFERENCES}

1. van der Knaap MS, Valk J, de Neeling N, Nauta JJ (1991) Pattern recognition in magnetic resonance imaging of white matter disorders in children and young adults. Neuroradiology, 33, 478-493.

2. Arnold DL, Matthews PM (1996) Practical aspects of clinical applications of MRS in the brain. In: MR Spectroscopy: Clinical Applications and Techniques. Edited by IR Young, HC Charles. London: Martin Dunitz. 139-159.

3. De Stefano N, Narayanan S, Matthews PM, Mortilla M, Dotti MT, Federico A, et al (2000) Proton MR spectroscopy to assess axonal damage in multiple sclerosis and other white matter disorders. J.Neurovirol., 6 Suppl 2, 121-129.

4. van der Knaap MS (2001) Magnetic resonance in childhood white-matter disorders. Dev Med Child Neurol, 43, 705-712.

5. Ross B, Bluml S (2001) Magnetic resonance spectroscopy of the human brain. Anatomical Records, 265, 54-84.

6. De Stefano N, Matthews PM, Antel JP, Preul M, Francis G, Arnold DL (1995) Chemical pathology of acute demyelinating lesions and its correlation with disability. Annals of Neurology, 38, 901-909.

7. Provencher SW (2001) Automatic quantitation of localized in vivo $1 \mathrm{H}$ spectra with LCModel. NMR in Biomedicine, 14, 260-264.

8. Austin SJ, Connelly A, Gadian DG, Benton JS, Brett EM (1991) Localized 1H NMR spectroscopy in Canavan's disease: a report of two cases. Magnetic.Resonance.in Medicine, 19, 439-445.

9. Grodd W, Krageloh-Mann I, Petersen D, Trefz FK, Harzer $K$ (1990) In vivo assessment of $N$-acetylaspartate in brain in spongy degeneration (Canavan's disease) by proton spectroscopy [letter]. Lancet, 336, 437-438.

10. Varho T, Komu M, Sonninen P, Holopainen I, Nyman S, Manner T, et al (1999) A new metabolite contributing to $N$ acetyl signal in $1 \mathrm{H}$ MRS of the brain in Salla disease. Neurology., 52, 1668-1672.

11. Morse RP, Kleta R, Alroy J, Gahl WA (2005) Novel form of intermediate salla disease: clinical and neuroimaging features. J Child Neurol., 20, 814-816.

12. Hanefeld FA, Brockmann K, Pouwels PJ, Wilken B, Frahm J, Dechent $P$ (2005) Quantitative proton MRS of Pelizaeus-Merzbacher disease: evidence of dys- and hypomyelination. Neurology., 65, 701-706.

13. Tedeschi G, Schiffmann R, Barton NW, Shih HH, Gospe SMJ, Brady RO, et al (1995) Proton magnetic resonance spectroscopic imaging in childhood ataxia with diffuse central nervous system hypomyelination. Neurology, 45, 15261532.

14. van der Knaap MS, Kamphorst W, Barth PG, Kraaijeveld CL, Gut E, Valk J (1998) Phenotypic variation in leukoencephalopathy with vanishing white matter. Neurology, 51, 540-547.

15. van der Knaap MS, Barth PG, Stroink $H$, van Nieuwenhuizen O, Arts WF, Hoogenraad F, et al (1995) Leukoencephalopathy with swelling and a discrepantly mild clinical course in eight children. Annals of Neurology, 37, 324-334. 16. Hanefeld F, Holzbach U, Kruse B, Wilichowski E, Christen HJ, Frahm J (1993) Diffuse white matter disease in three children: an encephalopathy with unique features on magnetic resonance imaging and proton magnetic resonance spectroscopy. Neuropediatrics, 24, 244-248.

17. van der Knaap MS, Barth PG, Gabreels FJ, Franzoni E, Begeer JH, Stroink H, et al (1997) A new leukoencephalopa- thy with vanishing white matter. Neurology, 48, 845-855. 18. De Stefano N, Balestri P, Dotti MT, Grosso S, Mortilla M, Morgese G, et al (2001) Severe metabolic abnormalities in the white matter of patients with vacuolating megalencephalic leukoencephalopathy with subcortical cysts. A proton MR spectroscopic imaging study. Journal of Neurology, 248, 403-409.

19. Kreis R, Pietz J, Penzien J, Herschkowitz N, Boesch C (1995) Identification and quantitation of phenylalanine in the brain of patients with phenylketonuria by means of localized in vivo $1 \mathrm{H}$ magnetic-resonance spectroscopy. J Magn Reson B, 107, 242-251.

20. Pietz J, Lutz T, Zwygart K, Hoffmann GF, Ebinger F, Boesch $C$, et al (2003) Phenylalanine can be detected in brain tissue of healthy subjects by $1 \mathrm{H}$ magnetic resonance spectroscopy. J Inherit.Metab Dis., 26, 683-692.

21. Leuzzi V, Tosetti M, Montanaro D, Carducci C, Artiola C, Carducci $C$, et al (2007) The pathogenesis of the white matter abnormalities in phenylketonuria. A multimodal 3.0 tesla MRI and magnetic resonance spectroscopy (1H MRS) study. J Inherit.Metab Dis., 30, 209-216.

22. van der Knaap MS, Wevers RA, Struys EA, Verhoeven NM, Pouwels PJ, Engelke UF, et al (1999) Leukoencephalopathy associated with a disturbance in the metabolism of polyols. Annals of Neurology, 46, 925-928.

23. Jan W, Zimmerman RA, Wang ZJ, Berry GT, Kaplan PB, Kaye EM (2003) MR diffusion imaging and MR spectroscopy of maple syrup urine disease during acute metabolic decompensation. Neuroradiology, 45, 393-399.

24. Sylvain M, Arnold DL, Scriver CR, Schreiber R, Shevell MI (1994) Magnetic resonance spectroscopy in NeimannPick disease type C: correlation with diagnosis and clinical responce to cholestyramine and lovastatin. Pediatric Neurology, 10, 228-232.

25. Battisti C, Tarugi $P$, Dotti MT, De SN, Vattimo A, Chierichetti F, et al (2003) Adult onset Niemann-Pick type $C$ disease: A clinical, neuroimaging and molecular genetic study. Mov Disord, 18, 1405-1409.

26. Shah DK, Tingay DG, Fink AM, Hunt RW, Dargaville PA (2005) Magnetic resonance imaging in neonatal nonketotic hyperglycinemia. Pediatric Neurology, 33, 50-52.

27. Viola A, Chabrol B, Nicoli F, Confort-Gouny S, Viout P, Cozzone PJ (2002) Magnetic resonance spectroscopy study of glycine pathways in nonketotic hyperglycinemia. Pediatric Research, 52, 292-300.

28. Gabis L, Parton P, Roche P, Lenn N, Tudorica A, Huang $W$ (2001) In vivo $1 H$ magnetic resonance spectroscopic measurement of brain glycine levels in nonketotic hyperglycinemia. J Neuroimaging. , 11, 209-211.

29. Heindel W, Kugel H, Roth B (1993) Noninvasive detection of increased glycine content by proton MR spectroscopy in the brains of two infants with nonketotic hyperglycinemia. AJNR Am J Neuroradiol., 14, 629-635.

30. Brockmann $K$, Bjornstad A, Dechent $P$, Korenke CG, Smeitink J, Trijbels JM, et al (2002) Succinate in dystrophic white matter: a proton magnetic resonance spectroscopy finding characteristic for complex II deficiency. Ann Neurol., 52, 38-46.

31. Stockler S, Holzbach U, Hanefeld F, Marquardt I, Helms $G$, Requart $M$, et al (1994) Creatine deficiency in the brain: a new, treatable inborn error of metabolism. Pediatric Research, 36, 409-413.

32. Schulze A (2003) Creatine deficiency syndromes. Mol.Cell Biochem., 244, 143-150. 
33. Bizzi A, Bugiani M, Salomons GS, Hunneman DH, Moroni I, Estienne $M$, et al (2002) X-linked creatine deficiency syndrome: a novel mutation in creatine transporter gene SLC6A8. Annals of Neurology, 52, 227-231.

34. Martin E, Capone A, Schneider J, Hennig J, Thiel T (2001) Absence of $N$-acetylaspartate in the human brain: impact on neurospectroscopy? Annals of Neurology, 49, 518 521.

35. Marcinek DJ (2004) Mitochondrial dysfunction measured in vivo. Acta Physiol Scand., 182, 343-352.

36. Arnold DL, Matthews PM, Francis GS, O'Connor J, Antel JP (1992) Proton Magnetic Resonance Spectroscopic Imaging for Metabolic Characterization of Demyelinating Plaques. Annals of Neurology, 31, 235-241.

37. Petroff $O A$, Graham GD, Blamire AM, al-Rayess $M$, Rothman DL, Fayad PB, et al (1992) Spectroscopic imaging of stroke in humans: histopathology correlates of spectral changes. Neurology, 42, 1349-1354.

38. Matthews PM, Andermann F, Silver K, Karpati G, Arnold DL (1993) Proton MR spectroscopic characterization of differences in regional brain metabolic abnormalities in mitochondrial encephalomyopathies. Neurology, 43, 24842490.

39. De Stefano N, Matthews PM, Ford B, Genge A, Karpati $G$, Arnold DL (1995) Short-term dichloroacetate treatment improves indices of cerebral metabolism in patients with mitochondrial disorders. Neurology, 45, 1193-1198.

40. Dubeau F, De Stefano N, Zifkin BG, Arnold DL, Shoubridge EA (2000) Oxidative phosphorylation defect in the brains of carriers of the tRNAleu(UUR) A3243G mutation in a MELAS pedigree. Annals of Neurology, 47, 179185.

41. Grosso S, Balestri P, Mostardini R, Federico A, De Stefano $N$ (2004) Brain mitochondrial impairment in ethylmalonic encephalopathy. J Neurol, 251, 755-756.

42. van der Knaap MS, van d, V, Barkhof $F$, van $C R$, Krageloh-Mann I, Feigenbaum A, et al (2003) A new leukoencephalopathy with brainstem and spinal cord involvement and high lactate. Annals of Neurology, 53, 252258.

43. Coburn B (2004) A rare disorder, ethylmalonic encephalopathy, is caused by mutations in a mitochondrial protein. Clinical Genetics, 65, 460-462.

44. Scheper GC, van der KT, van Andel RJ, van Berkel CG, Sissler M, Smet J, et al (2007) Mitochondrial aspartyl-tRNA synthetase deficiency causes leukoencephalopathy with brain stem and spinal cord involvement and lactate elevation. Nat.Genet., 39 , 534-539.

45. De Stefano N, Dotti MT, Mortilla M, Federico A (2001) Magnetic resonance imaging and spectroscopic changes in brains of patients with cerebrotendinous xanthomatosis. Brain, 124, 121-131.

46. Federico A, Dotti MT, Volpi N (1991) Muscle mitochondrial changes in cerebrotendinous xanthomatosis [letter]. Annals of Neurology, 30, 734-735.

47. Dotti MT, Manneschi L, Federico A (1995) Mitochondrial enzyme deficiency in cerebrotendinous xanthomatosis. Journal of the Neurological Sciences, 129, 106-108.

48. Kolodny EH (1993) Dysmyelinating and demyelinating conditions in infancy. [Review]. Current Opinion in Neurology $\theta$ Neurosurgery, 6, 379-386.

49. Koopmans RA, Li DK, Zhu G, Allen PS, Penn A, Paty $D W$ (1993) Magnetic resonance spectroscopy of multiple sclerosis: in-vivo detection of myelin breakdown products [letter]. Lancet, 341, 631-632.
50. Narayana PA, Doyle TJ, Lai D, Wolinsky JS (1998) Serial proton magnetic resonance spectroscopic imaging, contrast- enhanced magnetic resonance imaging, and quantitative lesion volumetry in multiple sclerosis. Annals of Neurology, 43, 56-71.

51. Davies SE, Newcombe J, Williams SR, McDonald WI, Clark JB (1995) High resolution proton NMR spectroscopy of multiple sclerosis lesions. Journal.of.Neurochemistry., 64, 742-748.

52. De Stefano N, Matthews PM, Arnold DL (1995) Reversible decreases in $N$-acetylaspartate after acute brain injury. Magnetic Resonance in Medicine, 34, 721-727.

53. Kruse B, Hanefeld F, Christen HJ, Bruhn H, Michaelis T, Hanicke W, et al (1993) Alterations of brain metabolites in metachromatic leukodystrophy as detected by localized proton magnetic resonance spectroscopy in vivo. Journal of Neurology, 241, 68-74.

54. van der Voorn JP, Pouwels PJ, Hart AA, Serrarens J, Willemsen MA, Kremer HP, et al (2006) Childhood white matter disorders: quantitative MR imaging and spectroscopy. Radiology., 241, 510-517.

55. Pizzini F, Fatemi AS, Barker PB, Nagae-Poetscher LM, Horska A, Zimmerman AW, et al (2003) Proton MR spectroscopic imaging in Pelizaeus-Merzbacher disease. AJNR Am J Neuroradiol., 24, 1683-1689.

56. Bruhn H, Kruse B, Korenke GC, Hanefeld F, Hanicke W, Merboldt KD, et al (1992) Proton NMR spectroscopy of cerebral metabolic alterations in infantile peroxisomal disorders. Journal of Computer Assisted Tomography, 16, 335-344.

57. Johannik $K$, Van Hecke P, Francois B, Marchal G, Smet MH, Jaeken J, et al (1994) Localized brain proton NMR spectroscopy in young adult phenylketonuria patients. Magnetic Resonance in Medicine, 31, 53-57.

58. Tzika AA, Ball WS, Jr., Vigneron DB, Dunn RS, Nelson SJ, Kirks DR (1993) Childhood adrenoleukodystrophy: assessment with proton MR spectroscopy. Radiology, 189, 467480.

59. Matthews PM, De Stefano N, Narayanan S, Francis GS, Wolinsky JS, Antel JP, et al (1998) Putting magnetic resonance spectroscopy studies in context: axonal damage and disability in multiple sclerosis. Semin.Neurol., 18, 327-336. 60. Bjartmar C, Battistuta J, Terada N, Dupree E, Trapp BD (2002) $N$-acetylaspartate is an axon-specific marker of mature white matter in vivo: a biochemical and immunohistochemical study on the rat optic nerve. Annals of Neurology, 51, 51-58.

61. Moffett JR, Ross B, Arun P, Madhavarao CN, Namboodiri AM (2007) N-Acetylaspartate in the CNS: from neurodiagnostics to neurobiology. Prog.Neurobiol., 81, 89-131.

62. Moser HW, Barker PB (2005) Magnetic resonance spectroscopy: a new guide for the therapy of adrenoleukodystrophy. Neurology, 64, 406-407.

63. Leone P, Janson CG, Bilaniuk L, Wang Z, Sorgi F, Huang $L$, et al (2000) Aspartoacylase gene transfer to the mammalian central nervous system with therapeutic implications for Canavan disease. Annals of Neurology, 48, 27-38. 64. Moats RA, Moseley KD, Koch R, Nelson M, Jr. (2003) Brain phenylalanine concentrations in phenylketonuria: research and treatment of adults. Pediatrics, 112, 1575-1579. 65. De Stefano N, Filippi M, Miller DH, Pouwels PJ, Rovira A, Gass A, et al (2007) Guidelines for Using Proton MR Spectroscopy in Multicentre Clinical MS Studies. Neurology, In Press 